\title{
Friendship Group Activities: Voices from Chinese EFL Learners
}

\author{
Jia Wang $^{1}$ \\ ${ }^{1}$ School of Education, University of Nottingham, UK \\ Correspondence: Jia Wang, School of Education, University of Nottingham, UK.
}

Received: November 23, 2020

Accepted: December 28, 2020 Online Published: December 29, 2020

doi: $10.5539 /$ elt.v14n1p140

URL: https://doi.org/10.5539/elt.v14n1p140

\begin{abstract}
Friendship group activities, as one of the learner-centered applications of collaborative learning, promotes learners' overall abilities and have been warmly welcomed into English as a foreign language (EFL) classes in China. However, because of the complexity of the multi-level classroom life, sometimes this application becomes problematic in the actual practice. To tackle this problem and illustrate the dynamic characteristics of collaborative language learning, further investigation into friendship groups from the students' perspective is necessary. The present study was conducted through qualitative research with six semi-structured interviews, which aimed to elicit learners' in-depth views on group work in the actual language classrooms and create a more suitable facilitative classroom environment for future students. The findings show that the fundamental factors, such as culture, teacher guidance and group processing have significantly impacted students' performance and participation. This impact may have important implications for implementing collaborative language learning in future EFL contexts.
\end{abstract}

Keywords: group work, collaborative learning, EFL context, student perceptions, culture, group dynamics

\section{Introduction}

To meet the demand of globalisation, China has witnessed a revised English curriculum development in the educational system, which introduced three themes in learning: 'autonomy, collaboration, and exploration' (Li et al., 2014). To correspond to this educational reform and improve students' communicative competence, more teachers introduce communicative language teaching (CLT) and collaborative learning (CL) as part of the syllabus design in universities (Lin, 2015; Hsieh, 2020). Friendship group activities, as one of the most popular patterns, have been warmly welcomed by EFL classes in China.

Although this flexible grouping method can satisfy students' healthy working habits and build their friendship (Lou et al., 1992), sometimes orchestrating effective friendship groups is somewhat challenging. The potential obstacles, such as off-task conversation (Hsieh, 2017), free-riding (Wang, 2012), the washback of the exams (Wall, 2009), the ritual of memorising, and mimicking habits (Han \& Yin, 2016) may lead to dysfunctional problems. Accordingly, it is very important to explore the quality of students' learning experience in the real learning context. However, the well-documented research regarding friendship group activities was mostly paid attention to general classroom practice instead of exploring students' actual experience. Facing this gap, the current study makes a major contribution to research on friendship group activities by demonstrating students' views in Chinese EFL contexts and then recommend areas of future research.

This study is composed of five parts. After this section, the paper moves on a review of literature which includes conceptual and theoretical support of collaborative learning as well as the nature of Chinese students. The remaining part of the paper proceeds as follows: research methodology, results, discussion, and conclusion. With a qualitative research method, this paper will answer the following two questions:

1. What are the advantages and disadvantages of friendship group activities described by EFL students?

2. What do students suggest for friendship group activities to improve the effectiveness of CL in future EFL teaching and learning?

\section{Literature Review}

\subsection{The Conceptual Perspective: Exploring Collaboration}

The collaborative learning (CL) model was originated in the 1970s and became a vital classroom teaching strategy the United States (Kessler, 1992). After 20 years of practice, the form of CL has matured and is now 
used in broader contexts, especially in universities (Johnson et al., 1990). Lin (2015) describes the collaboration as an umbrella term that embraces a variety of activities, such as friendship groups. Compared to learning individually, CL occurs when multiple people learn together (Dillenbourg, 1999), among which friendship group activity is one of its humanistic strategies that students can choose teammates according to their own wishes (Antil et al., 1998). However, it is still necessary to draw more specific parameters around students' behaviours. This research focuses on the collaboration that takes place among several students who work together with shared responsibilities and joint efforts, to reach a common goal (Nicolson et al., 2011). This definition extends into a classroom setting, where the effective interactions occur, and learning mechanisms among group members are triggered.

Recent studies on a universal scale have specified numerous uses for teamwork in EFL classrooms, practical and pedagogical facets have obtained continuous attention these years. For practical reasons, many studies have verified the effectiveness of group work on facilitating classroom management (Evertson \& Weinstein, 2006), creating pleasant atmospheres (Campion et al., 1993), establishing rapport (Anil \& Charatdao, 2012) through classroom observations. Pedagogically, the most popular research on group work is related to its impact on improving students' oral skills through peer interaction (Bentley, 2020).

Nevertheless, groups have a 'life of their own' (Dörnyei \& Murphey, 2008). In real practice, their characteristics are dynamic according to the complex and multifaceted classroom life (Tasca, 2020; Tudor, 2001). Thus, building a qualified group with the reflection of group dynamics is necessary. Johnson and Johnson (2009) highlight the four essential qualities of an effective group: positive interdependence, individual accountability, appropriate use of social skills, and group processing.

First of all, positive interdependence occurs when the group members are bonded together and share a common goal to achieve the task (Lin, 2015). A successful group is dependent on the efforts of all its members (Arnold, 1999). The stronger the interdependence is, the stronger the sense of belonging the students perceive.

In addition, personal responsibility occurs when members can take charge of their learning and contribute to the group (Arnold, 1999). When members are individually accountable, the group will be more cohesive. This term reflects the closeness that links each group member together (Dörnyei \& Murphey, 2008). Individual commitment is critical to cohesiveness, creating a pleasant group atmosphere and providing an internal 'gelling force' to the outcomes.

Furthermore, Salomon and Globerson (1989) indicate that group work allows the externalisation of the cognitive process. During this process, social facilitation is vitally important. As active participants, learners gain command of different social skills, such as clarifying, summarising, turn-taking, and expressing themselves, all of which are beneficial to CL development (Lin, 2015).

Finally, as a variable step mediating the achievement of CL, group processing may be defined as 'a review of a group session to describe the member actions that were helpful or unhelpful to decide what actions to continue or change' (Johnson et al., 1990). This concept highlights the effectiveness of peers' joint efforts during the group process (Slavin, 2015). In a mature group, members are expected to participate and contribute equally. Johnson and Johnson (2008) also propose the combination of instructor and participant processing, which may lead to greater problem-solving success.

\subsection{The Theoretical Perspective: Exploring the Foundation of Group Work}

The conceptual ideas of collaboration described above provide a promising image of group work. Still, a rich set of learning theories as the concrete foundation, undoubtedly increase the success of group work. This subsection introduces the theoretical support behind this interactive activity from two perspectives: social constructivist and second language acquisition (SLA). These alternative perspectives can be regarded as complementary rather than contradictory, aiding the achievement effects of CL (Slavin, 2015).

\subsubsection{Social Constructivist Perspective}

Collaboration in $\mathrm{CL}$ is closely related to constructivism, which indicates that students can assimilate the new information into their pre-existing knowledge by building personal and mental representations (Piaget, 1988). During this process, learners internalise what they have learned by transforming their functions (Vygotsky, 1978), rather than passively taking in information. Moreover, a socio-cultural view emphasises that learners mediate their learning according to the context and their experiences. Thus, when it comes to the classroom setting, social facilitation occurs when learners from different perspectives respond to conflicts to achieve higher levels of learning (Mercer, 2007).

During this socio-cultural milieu, scaffolding (Vygotsky, 1978) can be viewed as an essential vehicle that 
mediates both individual cognitive growth and social interactions. This metaphor was first introduced to refer to flexible and meaningful support provided by more knowledgeable others (MKO) (Wood et al., 1976) or ushering learners into the zone of proximal development (ZPD). By using appropriate scaffolding techniques with adjustments during the interaction, the MKO can bring their partners closer to their next-stage transition. As groups include many individuals, diverse learners with an abundance of ZPDs can bring different knowledge to the classroom. Through the communicative toolkit, learners can reach their potential accomplishable levels, after which they can achieve an inner-thinking process and realise an upper level of cognitive development.

In addition, the concept of 'learning' in CL is considered to be proactive and constructive. Learners, during this learning process, are no longer audiences and spectators but actors and performers (Cope \& Kalantzis, 2009; Osman et al., 2011). What is more, this process of learning is dynamic, influenced by the rich contextual possibilities (Brown et al., 1989). As reflective practitioners, learners need to expand their practice, such as problem-solving skills and reasoning, in order to develop their long-term learning potential. In other words, in collaborative activities, learners should participate in creating new knowledge and contributing to the construction of social networks, rather than passively accepting ideas.

\subsubsection{SLA Perspective}

Another learning theory that embraces group work draws on SLA-related research. A basic viewpoint of studying learners' language achievement originates from Krashen's comprehensible input hypothesis (Krashen, 1985). This assumption posits that a learner's language development depends on messages that are contained slightly above their current language level but acceptable to infer meaning. Group work is a creative process that makes use of comprehensible input and testing. Therefore, learners can come into contact with newly acquired knowledge and apply a structure to it (Hedge, 2008). Besides, Swain (1985) described in the output hypothesis that learners also need to produce comprehensible output while acquiring input. Likewise, Long (2009) highlighted further that, in aiming to make the output more understandable, 'modified interaction' and 'negotiation for meaning' are vitally important to drive second language (L2) learning. The strategies, such as comprehension checks or clarification checks, can maintain the flow of dialogue and repair conversational breakdowns (Richards \& Rodgers, 2014). Through negotiation and corrective feedback, learners can move forward in their second-language learning process.

These strands of SLA theory demonstrate that language learning and use can co-occur when engaging in collaborative dialogues (Lightbown \& Spada, 2013). Learners can produce more accurate and appropriate language while providing meaningful input for other members (Hedge, 2008). This is why CL has become so important in contemporary language classes.

\subsection{The Nature of Chinese Learners}

Because of the complexity of multifaceted classroom life, the consequences of group work cannot be the same all the time. Implying such a dynamic interactive activity, some contextual factors, such as social, cultural, and institutional effects, may influence students' perceptions and performance during the process. Figure 1 shows a summary of Chinese learners' characters.

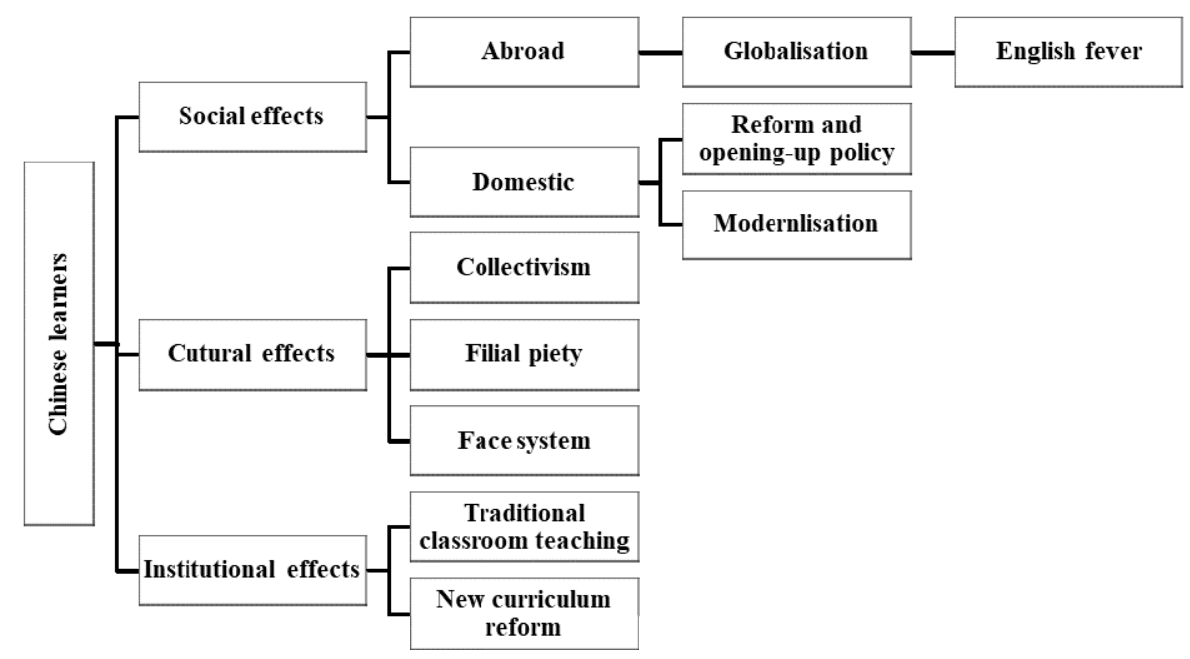

Figure 1. The Nature of Chinese Students 
Other than the institutional effects aforementioned in the introduction, we may need to draw attention to social effects when analysing the nature of Chinese EFL learners. Not until after the rise of globalisation did people from different countries become a whole. Similarly, from the late 1970s, the Chinese government put forward 'Reform and Opening Up Policy' and modernisation, which could be regarded as a driving force to broader international cooperation (Lin, 2015). These effects trigger an English fever (Yu, 2001) in a variety of areas in China, such as employment, cultural exchanges, commerce, technology, research (Driscoll et al., 2013). Since then, people from all walks of life have realised that if they get command of English in an all-round way, it can be more beneficial to open doors to western countries. Thus, academic motivation springs from the ever-increasing demand for competent English users in society (Peng \& Woodrow, 2010).

Although Chinese society has experienced a state of change, China cannot ignore its considerable amount of EFL learners (Cheng, 2008). Because of the disappointing feature of the monoculture environment, most learners gain limited access to English from unauthentic materials and domestic teachers (Leki, 2001). More importantly, the time-honoured Confucian Heritage Cultural (CHC) inhibitions still influence students' learning habits (Wang, 2012). The following parts will introduce such a cultural influence in detail from collectivism, filial piety, and face system.

To begin with, the definition of collectivism emphasises the priority given to a larger group in contrast to an independent entity (Yamagishi et al., 1998). This cultural feature, as an essential part of CHC, emphasises companionship and emotional interdependence ( $\mathrm{Li}$ et al., 2014). One of the most prominent applications in group work is that Chinese students always shoulder responsibilities to bring honour to the groups. This indeed sheds light on CL and the group cohesiveness. Students show their minds and hearts maximising the individual roles ( $\mathrm{Li}, 2002)$ to contribute to mutual goals. However, students sometimes focus on the community by sacrificing individual fulfilment. Rao (2007) illustrates that when collectivism adapts in the harmonious society, it may go strays. For example, learners sometimes hinder different voices, causing a possible danger to critical thinking ability.

Secondly, filial piety, which demonstrated by Woodrow and Sham (2001), is the virtues of 'respect for elders and supervisors', and 'loyalty and filial piety'. Accordingly, in educational contexts, teachers, as the more experienced entities, are held in high regard and respected by students. Since Chinese students traditionally view teachers as the source of wisdom (Miao, 2016), they believe teachers are the authority in the class and should be the centre to lead students, deliver knowledge and give answers. However, in the long run, students are willing to fall into 'rote, reticent, and passive learning' (Wang \& Liao, 2017), making CL like 'new bottles, old wines'. Furthermore, the learning behaviours, such as repetition, drills, make students view learning as a severe undertaking requires their painstaking efforts and deep commitments, somewhat decreasing their intrinsic motivation (Peng \& Woodrow, 2010).

The third feature relates to face concerns. The public image is so salient that it not only concerns ones' private matters but also regulates people's relationship and social networks (Fang, 2003). Therefore, some students feel anxious about speaking in front of the class or being asked questions by their teachers. Another effect can be seen in the discourse system. As opposed to the Utilitarian language system that seeks brevity and clarity in western culture (Lv, 2018), Chinese learners are accustomed to 'think thrice before acting' (Wang, 2012). They are more likely to leave room in communication as a way to protect the harmony and face images, e.g. implicitness or non-verbal communication. This model serves as a solid foundation for Chinese learners' conflict-avoidance resolution from the CHC (Chen \& Starosta, 1997).

This review highlights key literature, defines what group work means step by step, and critically reviews the contextual factors in this paper. However, the well-documented studies of group work paid little attention to students' opinions. To fill this gap, the current paper aims to examine the students' perspectives on how this activity as applied in Chinese EFL contexts and give some recommendations areas of future research. To answer the research questions previously mentioned in the introduction, my research applied an inductive qualitative approach by conducting semi-structured interviews which are introduced in the following chapter.

\section{Research Method}

\subsection{Participants}

Using convenience sampling strategy, I chose six participants (P1-P6) who met the criteria (as shown in Table 1) to join my research. Table 2. contains all their background information. 
Table 1. Sampling Framework

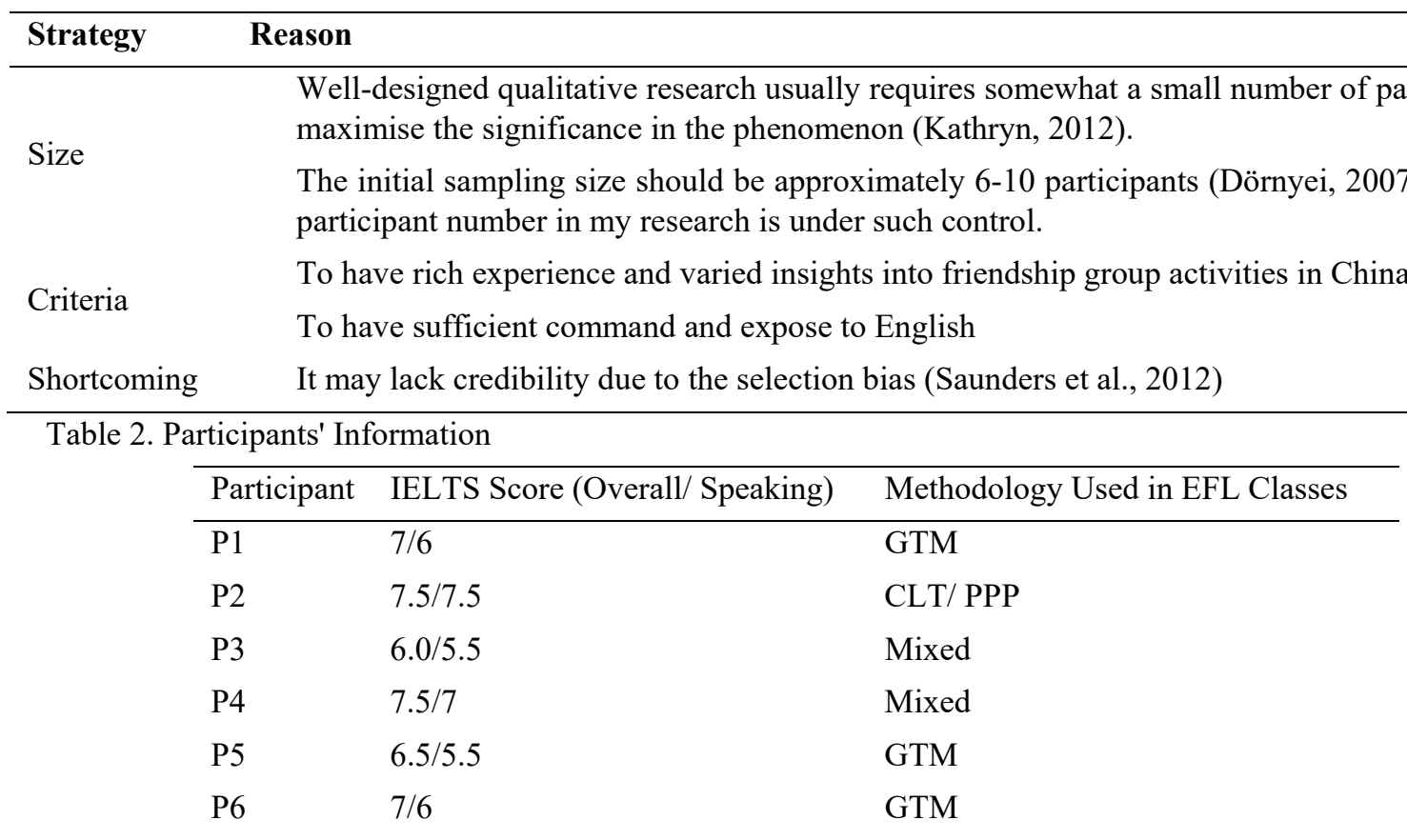

\subsection{Semi-Structured Interviews}

Six in-depth semi-structured interviews were conducted in this study to explore students' perceptions of friendship group activities in depth based on their experience. To design the data collection in a well-considered way, I planned an interview schedule considering an interactive model for this study. Three main question categories were developed, moving from general to specific. Instead of a simple framework, this part was supported by a critical view and theoretical evidence.

Before I started recording, I explained the aims and rationale of the interview again in both Chinese and English. Afterwards, I introduced the interview by proposing opening questions, including demographic information. In this way, a natural springboard for further questions was given (Richards, 2003) in a comfortable atmosphere, which is beneficial in encouraging a reasonably lengthy reply. During the interview, students were first asked to describe their most impressing friendship grouping experiences in detail, which were followed by a question of their real feelings accordingly. The remaining two questions are related to eliciting the strengths and weaknesses of friendship groups as well as recommendations.

\subsection{Data Analysis}

In terms of data analysis, I focused on three stages of this process: transcribing, developing ideas with memos, and coding. According to Coffey and Atkinson (1996), 'a basic principle of qualitative research should be conducted simultaneously with data collection'. As a result, I conducted these three stages at the same time. To simplify the lengthy transcriptions and explore the meaningful data in depth, I chose a thematic analysis method, which organises rich data sets by deconstructing them into categories and promote the discovery of basic themes (Gibbs, 2007). This method is sufficient to discover people's perceptions, experiences, and values, which are suitable for the statement in my discussion. Next, I reported the data as well as the correlation between theory and analysis in the next part.

\section{Results and Discussion}

There are three themes in data analysis, which will be discussed in this chapter. Through the discussion, we can see how friendship group activities are applied in Chinese EFL contexts, and the research questions can be easily answered.

\subsection{Theme 1: Advantages}

A common view amongst interviewees was that friendship group activities in the Chinese EFL context significantly promote their learning. The similarities are mainly concluded in the following aspects: language development, positive interdependence, emotional development. 


\subsubsection{Language Development}

In all cases, the participants reported that group interaction provided them with more opportunities to share ideas and communicate, which primarily benefits their language development. Consistent with the SLA perspective, learners negotiate their opinions and exchange ideas for more comprehensible input (Krashen, 1985) and modify their output to be more comprehensible to others (Swain, 1985). Because friendship groups provide students with more intimate, low-pressure settings (McCafferty et al., 2006), students are willing to speak and receive peers' feedback in group work. Thus, students felt 'not only their communicative competence, but also their listening abilities have greatly improved' (P5 and P6).

In addition, groups also develop social skills to help learners interact fairly with different groups of people. This view was echoed by P5, who concluded that this interactive activity 'promotes them to logically organise their thoughts, solve problems, ask for clarification, choose social strategies, and persuade others'.

\subsubsection{Positive Interdependence}

The positive interdependence from groups in both contexts promotes students as a unified whole that makes them feel bonded and intimately connected to (Johnson \& Johnson, 2009; Scager et al., 2016). One of the comments on this point from two contexts are as follows:

'My groupmates and I can make mutual efforts together towards the same goal. During the process,

I could learn from my peers.' (P1, P2, P4)

The description mentioned above is in line with the definition of CL, which stresses the importance of shared responsibilities, joint efforts, and mutual goals (Nicolson et al., 2011). The patterns, such as 'learning from peers', also indicate the idea that learning is a matter of supporting performance. With the use of peer scaffolding, 'individual learning interweaves with one another in a mutually supportive way as a whole learning community and gradually moves closer to its goal' (Little, 2001). Although it is somewhat inevitable that some learners in the group may not be good at the task itself, 'they can make full use of their wisdom to contributes to the group project, such as the technical problems' (P2). This aforementioned performance indicates that a group with positive interdependence can maximise each student's contributions and provide opportunities to build ZPDs (Arnold, 1999).

Besides, friendship grouping patterns bring benefits to build interdependent friendship and individual responsibilities. As P1 stated, they can know more people and learn how to maintain a friendship. CL indeed brings opportunities for students to act as resources for each other (Richards \& Rodgers, 2014). Besides, 'because everyone achieves the same goal' (P1), learners feel a strong moral responsibility to contribute to group success (Alfares, 2017), which leads to group cohesiveness and better personal development.

\subsubsection{Emotional Development}

The third positive influence of friendship grouping is the classroom climate. As suggested by P6, 'fear of losing face and appearing stupid' is the main threats of traditional classes. However, all informants reported that the cooperative incentive structures of group work create a supportive environment in which groupmates felt 'less embarrassed and anxious compared with speaking in public' (P3 and P6). In line with McCafferty et al. (2006), the 'safety of peer collaboration' (P4) can encourage participation surrounded by a 'welcoming atmosphere with motivation' (P5). Thus, learners can share ideas, exchange feedback, rehearse potential contributions to the larger group, increasing a greater likelihood of success.

Another impact is on improving learners' motivation. In cooperative groups, learners, especially for the shy and uninterested ones, can get help when making contributions. For example, P1 and P2 mentioned that they felt more motivated because they felt important. This result supports the previously observed evidence that groups activate learners' behaviour because they care for the groups and gain the benefits of self-identity from group members (Dörnyei \& Mercer, 2020; Slavin, 2015). More importantly, as P1 and P3 said, they are more enthusiastic because of the scaffolding of their peers, such as encouragement and appreciation. These factors can increase their self-efficacy because others admit them, while they are willing to help others, which drives to group cohesion and more interaction (Slavin 2015).

\subsection{Theme 2: Disadvantages}

\subsubsection{Lack of Group Processing}

The findings surprisingly show two extreme situations in learners' friendship group experience that are related to group processing. One of the results in 'some students who were active speakers and spoke all the time and never listened to others' (P1, P3, P4 and P5). In terms of the possible reasons, on the one hand, the reason 
illustrated by participants accord with Sutherland et al.'s (2019) observation. They stress that the misguided notion, the lack of time, teachers' unclear instruction may lead to forfeited group processing. Besides, as mentioned by P3, 'too much freedom' may be the essence of this imbalanced situations. Since Chinese students are somewhat lack of autonomous learning history and CL experience, the effectiveness of CL is easy to be reduced if teachers gave too much free time without appropriate monitoring and skills-training.

The other extreme runs counter to bringing students together but dividing up the class. P3 described the group that 'some students in the groups were in pair, some in six'. This finding is consistent with Johnson and Johnson's (2014) comment on pseudogroups. They indicate that the sum of the whole is less than the sum of the potential of the individual members. The group was not cohesive because students did not commit the group or interest in language learning. As P6 mentioned, not all of them studied English for interests and even some students only for getting a certificate.

Commenting on this, P5 said, 'not everyone cares about the quality of the conversation or solving the problems'. In line with Slavin (2015), who indicates that the quality of the groups' interaction is thought to be primarily depended by group cohesion. Thus, further friendship group activities should be undertaken to focus more on establishing group cohesion and learning interests during the process of CL.

\subsubsection{Teachers' Instruction}

According to the students' response, most Chinese EFL teachers' teaching is not satisfactory. On the one hand, due to the 'large size and limited time,' (P1 and P3), Chinese students have rather less time to take group activities but listen to teachers. Instead, mainstream teaching in China should leave enough space for students' exploration to benefit their lifelong learning despite the institutional factors. On the other hand, it is not surprising that the relationship between peers is somewhat totally individualistic. For example, P6 preferred talking with teachers or studying alone because he felt group work is 'a waste of time'. This may because some Chinese students view teachers as the authority and knowledge holders in their class, making the power and status in the classroom are unbalanced. Even for the limited friendship grouping experience in China, teachers normally 'do not join in groups but stand at the front' (P1 and P4). This is not helpful to improve the teacher-student relationship. This disappointing fact is contrary to social constructionism in 2.2.1, which highlights the cognitive development and critical thinking only improved through discussion that is amongst equals' (Piaget \& Gabain, 1997). The inequality in traditional classroom teaching may prevent students from expressing their critical ideas but pursue 'sacred knowledge ', which is useless for students' knowledge construction.

\subsubsection{Culture}

The third factor that influences most of the Chinese participants evaluated their grouping experience negatively owing to the deep-rooted traditional culture. Firstly, Chinese people care a lot about their public images. Although speaking in small groups somewhat decreases anxiety compared with speaking in public (Brown, 2001), concerns on 'face' still have deeply influenced some Chinese students' group performance, e.g. 'afraid of making mistakes' (P5 and P6).

Secondly, CHC highly respects 'harmony' (Wang, 2012), in which the learners in society are unwilling to challenge others' opinions to avoid conflict. On the one hand, 'learners think their answers could not contribute to the group. So, they do not want to share it with others.' (P4) However, this result was not very encouraging for learners' development in the long term. An example is as follows:

'Sometimes, I was in a group with a lot of high-level classmates. I do not want to say anything in this type of group because they were always right.' (P6)

This is a response to groupthink (Dörnyei \& Murphey, 2008) that learners may not only suppress their objections but may even reach the point where they are unaware of any objections. More seriously, this may preserve learners' ZPD construction and cognitive development. On the other hand, some Chinese learners focus much on establishing robust social networks (Wang, 2012). One example shows as follows:

'The point is if my friends want me to do all staffs and I could not say no. It is because of Chinese culture. Chinese tend to keep a good relationship with their peers and be friendly. In fact, it is unfair to me' (P1).

However, if more students sacrifice themselves for such companionships, more free riders that loaf on the efforts of their more conscientious groupmates (Dörnyei \& Murphey, 2008) will appear. The main reason for this drawback results from the washback of the exams (Wall, 2009). P1 claimed that 'many group members just did nothing, but finally, they can get a good result.' This data accords with Slavin's (2015) previous observation that 
group reward, e.g. marks, can encourage group achievement if they are given a single group product. The disappointing result makes those free riders neglected the use of L2 but only concentrated on the results of tasks. It is because the exams are so important that they will influence their GPA, future career, further education (P1 and P6). Canale and Swain (1980) pointed out that communicative testing had better contain not only what they know and how to use L2, but also how to apply them into an authentic situation. The compulsory exams make English became a way of getting results. This negatively made students, even MKOs lost interests and became demotivated (P1 and P4). For example, P4 felt exploited and spoke less later in the groups.

Thirdly, lack of language proficiency and knowledge had become one of the problems in group work practice in China. For example, some responses to this point included that 'the conversations were almost being Chinese rather than English' (P2). This may occur owing to Chinese monocultural environment where not too many Chinese students can enjoy the authentic resources directly.

Indeed, there is much evidence that might prove the negative Chinese cultural impact on group activities as discussed. However, one interviewee (P4) did not agree with the previous findings and viewed the cultural implications as stereotypes:

'I think a lot of people have a bias on Asian students. Although there is much evidence that Asian students are not engaged in groups. But if Chinese students speak up, they always feel surprised. I just think it is because of the low speaking volume' (P4).

Because of the limited number of participants in my interview, producing generalised conclusion about any particular idea should be careful. This is an unexpected outcome that has not been covered previously and should be seriously considered. Indeed, cultural learning is dynamic, and researchers should avoid common stereotypes. Despite the disadvantages in Chinese learners' passive behaviours (Li et al., 2014), recently there has been a significant amount of research which highlights Chinese students' significant improvement and better cultural adaptation (Wang, 2012). In addition, the difference between cultural expectations and individual differences should be figured out. As P5 and P6 noted, some learners themselves may be shy and quiet instead of influenced by traditional culture. The personality differences, learning styles or preferences may affect students' learning repertoire and CL performance (Arnold, 1999). These two points, therefore, enlighten me that the understanding of cultural influences on friendship group activities should be in a systematic way instead of judging people with bias and preconception.

\subsection{Theme 3: Suggestions}

After analysing six Chinese EFL learners' actual feelings on the friendship group practices, it is imperative to give some suggestions to future group work teaching and learning in China. The key aspects can be listed in the following aspects: teachers, students, and institutions.

\subsubsection{Teachers}

The first aspect is the teachers' instruction. First and the foremost, the majority of participants suggested that teachers' instructions should be clear and explicit, for example, 'giving models' (P3), 'releasing anxiety of making mistakes' (P5). This result may be explained by Mercer (2004), who illustrates that scaffolders should provide rich, stimulating support to students. In this way, students could comprehend the meaning and build their ZPD by friendship groups. The motivation, too, largely influence learners' involvement that should be noticed by teachers (P3 and P5). P5 explicitly gave one example for improving students' inspiration that teachers are expected to be the group leader so that students may be triggered to start the conversation. This finding was also reported by Dörnyei \& Mercer (2020) that 'teachers' actions are defining for the classroom climate and attitudes that develop in the class'. Teachers can mobilise students and set examples in groups, by aligning actions with shared values in groups.

Secondly, Chinese EFL teachers should consider fostering a culture of collaboration and support. As recommended by P1, 'teachers should let students share their opinions'. This is in line with the point that teachers had better protect each students' turn with prompts and scaffolds, and reminders to other learners to listen when grouping (Boblett, 2012). However, it does not mean that teachers should westernise their teaching methodology in the classroom. P5 indicated that Chinese teachers could flexibly change their instructions based on the specific session. This also accords with established literature, which showed that there exist dangers of applying western-based approaches that do not take cultural complexities into account (Nguyen et al., 2006).

The final suggestion for teachers is to pay attention to their professional standing. Scaffolding is bidirectional that not only exists between novice and expert peer interaction but also between teachers and students. P2 gave an example which shed light on the mutual effects on affective factors between teacher-students relationship: 
'Once teachers are more professional and confident, students will benefit more, and it is a mutual impact' (P2).

Teacher quality plays a vital role in promoting student achievement. However, Chinese college teachers in general conduct GTM teaching method because they are only familiar with teaching English in Chinese (Yu, 2001). Thus, in future classroom teaching, teachers should be undertaken to improve their professional standing to update their teaching and better facilitate students.

\subsubsection{Students}

The suggestions regarding on students mainly focus on improving their awareness of overall language proficiency rather than the linguistics only (P1). If learners want to learn the authentic language, they should use the language. This is supported by Hymes (1972) who indicates that 'both knowledge and ability for language use should be respect to whether something is appropriate concerning the context'. Furthermore, learners should foster a collaborative cultural concept (P1 and P6) so that they can be supportive of each other and embrace a festive group atmosphere for long-term benefits (Dörnyei \& Mercer, 2020).

\subsubsection{Institutions}

Regarding the institutional aspect, the recommendations from participants can be divided into two aspects: the group training and assessment reform. The first reasonable approach to improve group work could be to assign teambuilding training programmes, for both learners and teachers. This point was proposed by P4, who said as follows:

'If the training can be started as early as possible, students and teachers can be accustomed to CL and be good at these skills in the future' (P4).

This is in line with O'Malley \& Chamot (1990) who suggests a 'less is more' philosophy which focuses on the high-priority content in-depth while spending more time on developing their CL skills more frequently instead of for once. In particular, most participants demonstrated they are in dire need of group processing training in Chinese classrooms. Commenting on this, Arnold (1999) suggested that institutions should train teachers to involve post-instructional help after group activities, for example, giving students feedback. Likewise, learners should be trained to reflect upon their learning experience, noting how group members interacted doing those tasks, the kind and number of contributions each made, and difficulties that were encountered.

The second suggestion on institutions relates to the assessment. English becomes a way of utilitarianism and getting results for some Chinese students who neglected the significance of learning process. To solve this, P1 suggested, 'each member should get different scores depending on the jobs they did'. This accords with McKay (2006), who suggested that the effective assessment should provide students' feedback on their learning process and creates tension for them. Thus, policymakers should not only consider informing the students' learning process but also take accounts of the fairness of the group work evaluation.

\section{Conclusion}

This project was undertaken to investigate and evaluate the effectiveness of friendship group activities from students' viewpoints. Multiple perspectives revealed that this CL activity is a double-edged sword that brings both significant outcomes (e.g. positive interdependence, language and emotional development) as well as potential pitfalls (e.g. teachers' instruction, lack of group processing, cultural influence) for EFL classroom learning in China. Taken together, these findings suggest a role for teachers, students, and learners in promoting future CL application and for researchers in taking holistic and justified views when analysing cultural differences.

Although this study has proved useful in expanding our understanding of students' real opinions on friendship group activities in detail, because of the complexity of real classroom practice, groups are always dynamic. Due to practical constraints, this paper cannot provide a more comprehensive review of the application which may lack generalisation. Notwithstanding these limitations, the study firstly suggests that more information on teachers' perceptions would help us to triangulate a greater degree of accuracy on this matter. Secondly, future researchers are expected to further conduct class observations to trace students' further performances in a longitudinal study.

\section{References}

Alfares, N. (2017). Benefits and Difficulties of Learning in Group Work in EFL Classes in Saudi Arabia. English Language Teaching, 10(7), 247. https://doi.org/10.5539/elt.v10n7p247

Antil, L. R., Jenkins, J. R., \& Wayne, S. K. (1998). Cooperative learning: Prevalence, conceptualisations, and the 
relation between research and practice. American Educational Research Journal, 35(3). https://doi.org/10.3102/00028312035003419

Arnold, J. (Ed.). (1999). Affect in language learning. Cambridge University Press.

Boblett, N. (2012). Scaffolding: Defining the Metaphor. Applied Linguistics, 12(2), 1-16.

Brown, H. D. (2001). Teaching by principles: An interactive approach to language pedagogy (2nd ed.). Longman.

Brown, J. S., Collins, A., \& Duguid, P. (1989). Situated Cognition and the Culture of Learning. Educational Researcher, 18(1), 32-42. https://doi.org/10.3102/0013189X018001032

Canale, M., \& Swain, M. (1980). Theoretical Bases of Communicative Approaches to Second Language Teaching and Testing. Applied Linguistics, I(1), 1-47. https://doi.org/10.1093/applin/I.1.1

Chen, G., \& Starosta, W. (1997). Chinese conflict management and resolution: Overview and implications. Intercultural Communication Studies, 7(1), 1-16.

Cheng, L. (2008). The key to success: English language testing in China. Language Testing, 25(1), 15-37. https://doi.org/10.1177/0265532207083743

Cope, B., \& Kalantzis, M. (2009). Multiliteracies: New Literacies, New Learning. Pedagogies: An International Journal, 4(3), 164-195. https://doi.org/10.1080/15544800903076044

Dörnyei, Z. (2007). Research methods in applied linguistics: Quantitative, qualitative, and mixed methodologies. Oxford University Press.

Dörnyei, Z., \& Mercer, S. (2020). Engaging language learners in contemporary classrooms. Cambridge University Press.

Dörnyei, Z., \& Murphey, T. (2008). Group dynamics in the language classroom (Nachdr.). Cambridge University Press.

Driscoll, P., Earl, J., \& Cable, C. (2013). The role and nature of the cultural dimension in primary modern languages. Language, Culture and Curriculum, 26(2), 146-160. https://doi.org/10.1080/07908318.2013.799675

Fang, T. (2003). A Critique of Hofstede's Fifth National Culture Dimension. International Journal of Cross-Cultural Management, 3(3), 347-368. https://doi.org/10.1177/1470595803003003006

Gibbs, G. (2007). Analyzing Qualitative Data. SAGE Publications, Ltd. https://doi.org/10.4135/9781849208574

Han, J., \& Yin, H. (2016). College English Curriculum Reform in Mainland China: Contexts, Contents and Changes. Asian Education Studies, 1(1), 1. https://doi.org/10.20849/aes.v1i1.9

Hedge, T. (2008). Teaching and learning in the language classroom. Oxford University Press.

Hsieh, Y. C. (2017). A case study of the dynamics of scaffolding among ESL learners and online resources in collaborative learning. Computer Assisted Language Learning, 30(1-2), 115-132. https://doi.org/10.1080/09588221.2016.1273245

Hsieh, Y. C. (2020). Learner interactions in face-to-face collaborative writing with the support of online resources. ReCALL, 32(1), 85-105. https://doi.org/10.1017/S0958344019000120

Johnson, D. W., \& Johnson, F. P. (2014). Joining together: Group theory and group skills.

Johnson, D. W., \& Johnson, R. T. (2009). An Educational Psychology Success Story: Social Interdependence Theory and Cooperative Learning. Educational Researcher, 38(5), 365-379. https://doi.org/10.3102/0013189X09339057

Johnson, D. W., Johnson, R. T., Stanne, \& Garibaldi, A. (1990). Impact of Group Processing on Achievement in Cooperative Groups. The Journal of Social Psychology, 130(4), 507-516. https://doi.org/10.1080/00224545.1990.9924613

Kathryn, R. (2012). Interviews in Qualitative Research. In C. A. Chapelle (Ed.), The Encyclopedia of Applied Linguistics (1st ed.). Wiley. https://doi.org/10.1002/9781405198431

Kessler, C. (Ed.). (1992). Cooperative language learning: A teacher's resource book. Prentice Hall Regents.

Leki, I. (2001). A Narrow Thinking System: Nonnative-English-Speaking Students in Group Projects across the Curriculum. TESOL Quarterly, 35(1), 39. https://doi.org/10.2307/3587859 
Li, D., Remedios, L., \& Clarke, D. (2014). Chinese students' groupwork practices and experiences in China. Higher Education, 68(2), 227-241. https://doi.org/10.1007/s10734-013-9704-y

Li, J. (2002). A Cultural Model of Learning: Chinese 'Heart and Mind for Wanting to Learn'. Journal of Cross-Cultural Psychology, 33(3), 248-269. https://doi.org/10.1177/0022022102033003003

Lightbown, P., \& Spada, N. M. (2013). How languages are learned (Fourth edition). Oxford University Press.

Lin, L. (2015). Investigating Chinese HE EFL Classrooms: Using Collaborative Learning to Enhance Learning. https://doi.org/10.1007/978-3-662-44503-7

Little, D. (2001). Learner autonomy and human interdependence: Some theoretical and practice consequences of a social-interactive view of cognition, learning, and language. In B. Sinclair, I. McGrath, \& T. Lamb (Eds.), Learner autonomy, teacher autonomy: Future directions (pp. 15-23). Longman.

Long, M. H. (2009). The role of linguistic environment in second language acquisition. In W. C. Ritchie \& T. K. Bhatia (Eds.), The new handbook of second language acquisition (pp. 413-468). Emerald. https://doi.org/10.1016/B978-012589042-7/50015-3

Lou, Y., Abrami, P. C., \& Spence, J. C. (1992). Within-Class Grouping: A Meta-Analysis. Review of Educational Research, 66(4), 423-458. https://doi.org/10.3102/00346543066004423

Lv, L. (2018). Role of Email in Intercultural Communication of Criticism in a Chinese English Curriculum Reform Context. English Language Teaching, 11(2), 193. https://doi.org/10.5539/elt.v11n2p193

McKay, P. (2006). Assessing young language learners. Cambridge University Press. https://doi.org/10.1017/CBO9780511733093

Mercer, N. (2004). Words and minds: How we use language to think together. Routledge.

Mercer, N. (2007). Dialogue and the Development of Children's Thinking: A Sociocultural Approach. Routledge. https://doi.org/10.4324/9780203946657

Miao, Y. (2016). A Study of the Differences Between China and UK Classroom Teaching in Middle Schools Based on a BBC Documentary. Sino-US English Teaching, 13(11), 856-859. https://doi.org/10.17265/1539-8072/2016.11.004

Nguyen, P., Terlouw, C., \& Pilot, A. (2006). Culturally appropriate pedagogy: The case of group learning in a Confucian Heritage Culture context. Intercultural Education, 17(1), 1-19. https://doi.org/10.1080/14675980500502172

Nicolson, M., Murphy, L., \& Southgate, M. (Eds.). (2011). Language Teaching in Blended Contexts. Dunedin Academic Press.

Osman, G., Duffy, T. M., Chang, J., \& Lee, J. (2011). Learning through collaboration: Student perspectives. Asia Pacific Education Review, 12(4), 547-558. https://doi.org/10.1007/s12564-011-9156-y

Peng, J. E., \& Woodrow, L. (2010). Willingness to Communicate in English: A Model in the Chinese EFL Classroom Context: Willingness to Communicate in English. Language Learning, 60(4), 834-876. https://doi.org/10.1111/j.1467-9922.2010.00576.x

Piaget, J. (1988). Play, dreams, and imitation in childhood. W.W. Norton \& Co.

Piaget, J., \& Gabain, M. (1997). The moral judgement of the child. Free Press Paperbacks.

Rao, Z. (2007). Individual differences and cultural factors (Shanghai Foreign Language Education Press).

Richards, J. C., \& Rodgers, T. S. (2014). Approaches and methods in language teaching (Third edition). Cambridge University Press.

Salomon, G., \& Globerson, T. (1989). When teams do not function the way they ought to. International Journal of Educational Research, 13(1), 89-99. https://doi.org/10.1016/0883-0355(89)90018-9

Saunders, M. N. K., Lewis, P., \& Thornhill, A. (2012). Research methods for business students (6th ed.). Pearson.

Scager, K., Boonstra, J., Peeters, T., Vulperhorst, J., \& Wiegant, F. (2016). Collaborative Learning in Higher Education: Evoking Positive Interdependence. CBE-Life Sciences Education, 15(4). https://doi.org/10.1187/cbe.16-07-0219

Slavin, R. E. (2015). Cooperative learning in elementary schools. Education 3-13, 43(1), 5-14. https://doi.org/10.1080/03004279.2015.963370 
Sutherland, S., Stuhr, P. T., Ressler, J., Smith, C., \& Wiggin, A. (2019). A Model for Group Processing in Cooperative Learning. Journal of Physical Education, Recreation \& Dance, 90(3), 22-26. https://doi.org/10.1080/07303084.2019.1559676

Swain, M. (1985). Communicative competence: Some roles of comprehensible input and comprehensible output in its development. In S. M. Gass \& C. G. Madden (Eds.), Input in second language acquisition (pp. 235-253). Newbury House Publishers.

Tasca, G. A. (2020). What is group dynamics? Group Dynamics: Theory, Research, and Practice, 24(1), 1-5. https://doi.org/10.1037/gdn0000115

Tudor, I. (2001). The Dynamics of the Language Classroom. Cambridge University Press.

Vygotsky, L. S. (1978). Mind in society: The development of higher psychological processes (Nachdr.). Harvard Univ. Press.

Wall, D. (2009). Washback. In The Routledge Handbook of Language Testing. Routledge. https://doi.org/10.4324/9780203181287.ch5

Wang, Y. (2012). Mainland Chinese students' group work adaptation in a UK business school. Teaching in Higher Education, 17(5), 523-535. https://doi.org/10.1080/13562517.2012.658562

Wang, Ya-huei, \& Liao, H.-C. (2017). Learning Performance Enhancement Using Computer-Assisted Language Learning by Collaborative Learning Groups. Symmetry, 9(8), 141. https://doi.org/10.3390/sym9080141

Wood, D., Bruner, J. S., \& Ross, G. (1976). The role of tutoring in problem solving. Child Psychiatry and Psychology, 17(2), 89-100. https://doi.org/10.1111/j.1469-7610.1976.tb00381.x

Woodrow, D., \& Sham, S. (2001). Chinese Pupils and Their Learning Preferences. Race Ethnicity and Education, 4(4), 377-394. https://doi.org/10.1080/13613320120096661

Yamagishi, T., Jin, N., \& Miller, A. S. (1998). In-group Bias and Culture of Collectivism. Asian Journal Of Social Psychology, 1(3), 315-328. https://doi.org/10.1111/1467-839X.00020

Yu, L. (2001). Communicative Language Teaching in China: Progress and Resistance. TESOL Quarterly, 35(1), 194. https://doi.org/10.2307/3587868

\section{Copyrights}

Copyright for this article is retained by the author(s), with first publication rights granted to the journal.

This is an open-access article distributed under the terms and conditions of the Creative Commons Attribution license (http://creativecommons.org/licenses/by/4.0/). 